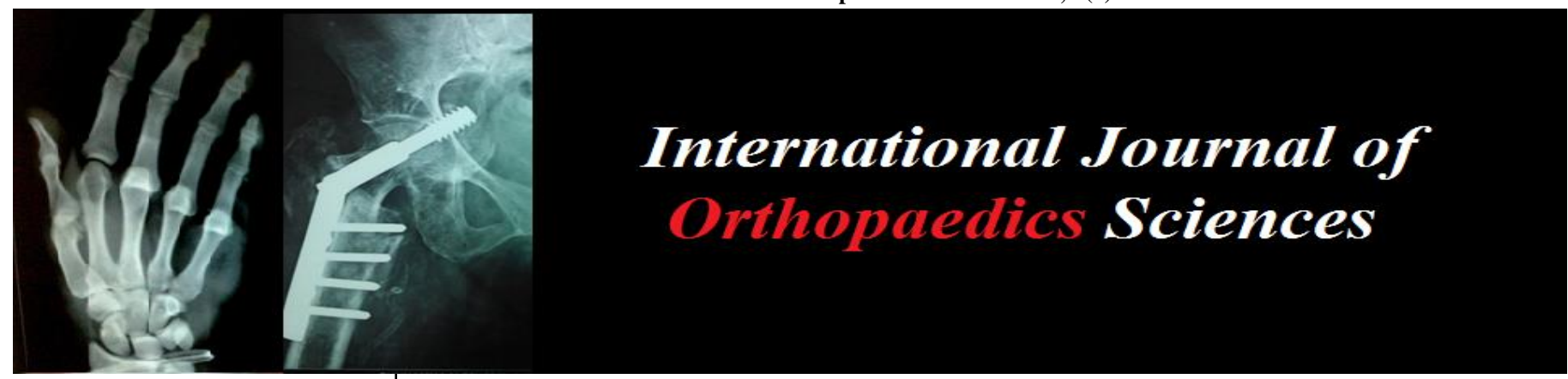

ISSN: $2395-1958$

IJOS 2019; 5(3): 257-262

(C) 2019 IJOS

www.orthopaper.com

Received: 01-05-2019

Accepted: 05-06-2019

Roshan Raj KM

Post graduate, Dept. of

Orthopaedics, Mahatma Gandhi

Medical College \& Research

Institute, Puducherry, India

Nanda Kumar R

Professor, Dept. of Orthopaedics,

Mahatma Gandhi Medical

College \& Research Institute,

Puducherry, India

\section{Manoharan M}

Assistant Professor, Dept. of

Orthopaedics, Mahatma Gandhi

Medical College \& Research

Institute, Puducherry, India

\section{Correspondence}

Nanda Kumar R

Professor, Dept. of Orthopaedics,

Mahatma Gandhi Medical

College \& Research Institute,

Puducherry, India

\section{Comparison of functional outcome between expert tibial nail and distal tibial medial locking plate by mippo technique for closed extra articular distal tibial fracture}

\author{
Roshan Raj KM, Nanda Kumar R and Manoharan M
}

DOI: https://doi.org/10.22271/ortho.2019.v5.i3e.1536

\begin{abstract}
Background: Distal tibial fractures account for approximately $7 \%$ of all tibial fractures and can present a management challenge because of their inherent instability, scarcity of soft tissues, subcutaneous nature and poor vascularity of bone. Despite the availability of various modern techniques, there is either no or insufficient evidence to draw definitive conclusions on the best surgical intervention.

Materials and Methods: The study was an open labelled randomized control trial conducted over a period of one year from January to December 2017. Patients with extra-articular distal tibia fracture attending the Department of Orthopaedics, in tertiary care hospital through casualty or outpatient basis fulfilling the inclusion and exclusion criteria were the study participants. After obtaining necessary permissions and consent, the patients were randomized into two groups for IMIL nailing and plating. Data on socio-demographic characteristics, surgery details and complications were obtained. The functional outcomes were measured at 1, 3, 4, and 6 months by using Olreud \& Molander scale and RUST scale. The data obtained were entered into excel and analyzed using SPSS v16.

Results: A total of 32 patients (16 in each group) participated. The mean age of participants were 44.1 $( \pm 16.95)$ years and majority were males $(56.3 \%)$. Majority $(81.3 \%)$ patients had an associated fracture in the distal fibula. The time of surgery and fracture union for intramedullary nail was significantly less when compared to plating. The Olreud \& Molander scores and RUST scores were significantly higher in patients with IMIL nail. Malunion and anterior knee pain were more frequent after IM interlocking nail. Non-union and infection were found only in the plating group.

Conclusion: The study found intra-medullary inter-locking (IMIL) nailing was more successful and effective in terms of achieving good union with optimal functional outcomes compared to the extra medullary plating for closed extra-articular distal third tibial fractures. A larger sample size with equal representation in both groups is required for a $\mathrm{p}$ value with higher significance.
\end{abstract}

Keywords: Extra articular, distal tibia, plating, nailing, compare

\section{Introduction}

Distal tibial fractures are one of the most complex injuries around the ankle joint, accounting for approximately $7 \%$ of all tibial fractures ${ }^{[1]}$. Fractures of the distal tibial metaphysis with or without intra-articular extension can present a management challenge because of their inherent instability, scarcity of soft tissues, subcutaneous nature and poor vascularity of bone. Treatment modality is dictated by the fracture displacement, comminution, intra-articular extension and injury to the soft-tissue envelope ${ }^{[2]}$. Soft-tissue management has been seen to play a vital role in the management alongside the bony reconstruction ${ }^{[3]}$.

Open reduction and plating is a popular method that can result in good fixation. The technique is used widely, but it usually requires a relatively extensive wound exposure and soft-tissue dissection and is often associated with delayed healing, infection, and hardware problems ${ }^{[4]}$. Recently, minimally invasive percutaneous medial locked plating has been described in the literature with promising results. However, this method is technically demanding, and it is often difficult to achieve anatomic reduction ${ }^{[5,9]}$.

Expert tibia nails currently represent an effective approach to the treatment of complex extraarticular distal tibial fractures. The low multidirectional locked nailing may represent a 
superior surgical option, since it offers advantages in terms of full weight-bearing, union rate, short operating time and hospital sta ${ }^{[6,8]}$.

Despite the availability of various modern techniques, there is either no or insufficient evidence to draw definitive conclusions on the best surgical intervention for distal tibial metaphyseal fractures in adults. Hence, our study aims to compare the functional outcomes of distal metaphyseal fractures of tibia managed with Minimally Invasive Percutaneous Plate Osteosynthesis (MIPPO) and expert tibial intramedullary nailing.

\section{Materials and subjects}

The study was a randomized control trial conducted in the Department of Orthopaedics, in a tertiary care hospital between the periods from January 2017 to July 2018 after obtaining ethical clearance from the Institutional Human Ethical Committee (IHEC) project no.
Skeletally matured patients with fracture involving distal 1/3rd of tibia (AO type A1, A2, A3) were included in the study, Skeletally immature patients, Pilon fractures( AO type B,C) All open fractures, Associated fractures in ipsilateral limb excluding fibula and mentally ill patients were excluded from the study.

\section{Sampling Procedure}

The 32 patients with extra-articular distal tibial fracture and fulfilling the inclusion criteria were selected and verified. Informed and written consent were obtained. The patients were number sequentially at the time of admission and were randomized into two groups. Group one underwent expert tibial nail and group two underwent distal medial tibial locking plate for distal tibial fracture. The cost, pros and cons of both the procedure were explained prior to the surgery to the respective groups. Computer generated random numbers were used for randomizing the patients.

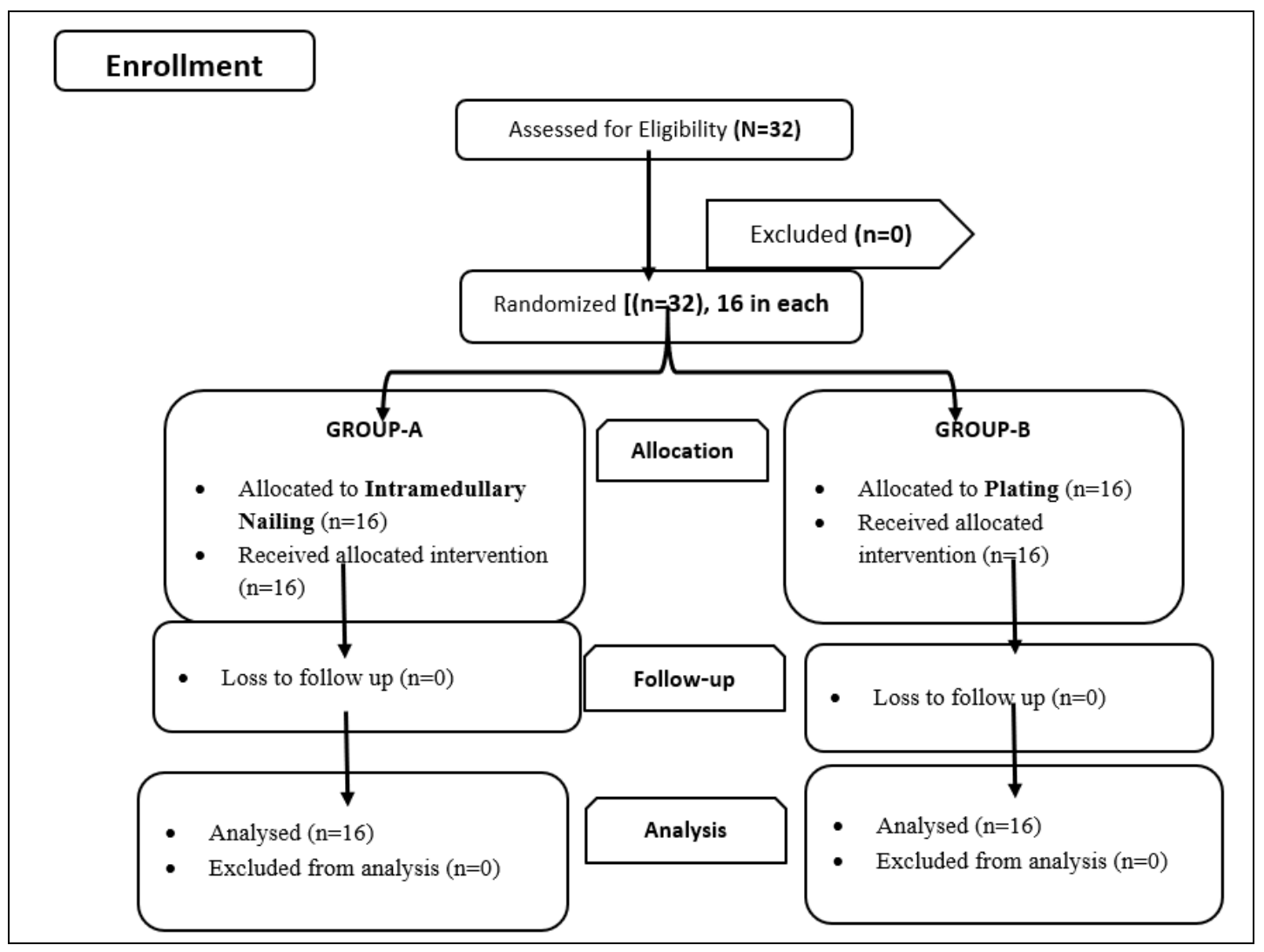

\section{Post-operative protocol}

Patient who were in nailing group was made to full weight bear as soon as possible, were as in plating group patient Clinical and radiological follow-up was done at end of 1month, 3 months, 6months and 12 months after the surgery. Standard antero-posterior and lateral view radiographs of the leg with knee and ankle joint were taken. All patients were covered with 3 doses of intravenous broad spectrum antibiotics. Dressing was removed and the wound was inspected on the 2 and 5 day after surgery and subsequently the sutures were removed on the 12 post-operative day.

The functional outcome was assessed using the OlreudMolander Ankle Score (OMAS) and the Radiographic Union Scale in Tibial fractures (RUST) score.

Data analysis and statistical tools

The data obtained from the proforma were entered into
Microsoft excel 2016 software and analysed using Statistical Package for Social Sciences (SPSS) version 16. Mean and standard deviation were calculated to summarize continuous variables such as age, time of surgery and time of union. The Olerud and Molander scores were summarized as number and percentages while the RUST scores were summarized as Mean and Standard deviation. Independent $t$ test was used to find the existence of significant differences in RUST scores among the two procedure groups.

\section{Results}

The present study was a randomized control trial to compare the functional outcome of expert tibial nail and distal tibial medial locking plate by MIPPO technique for the treatment of extra articular distal tibial fracture.

\section{Variables}


Table 1: Distribution of the socio-demographic variables, co-morbidities and surgery details among the two procedure groups

\begin{tabular}{|c|c|c|c|c|}
\hline Variables & $\begin{array}{c}\text { Group A } \\
\text { (Intramedullary Nail) n (\%) }\end{array}$ & $\begin{array}{c}\text { Group B } \\
\text { (Plating) n (\%) }\end{array}$ & Total, n (\%) & Chi-square ( $p$ value) \\
\hline Age & & & & \\
\hline $20-40$ years & $10(66.7)$ & $5(33.3)$ & $15(46.9)$ & \multirow{3}{*}{$3.2(0.257)$} \\
\hline $40-60$ years & $4(33.3)$ & $8(66.7)$ & $12(37.5)$ & \\
\hline$>60$ years & $2(40)$ & $3(60)$ & $5(15.6)$ & \\
\hline \multicolumn{5}{|c|}{ Gender } \\
\hline Male & $8(44.4)$ & $10(55.6)$ & $18(56.3)$ & \multirow{2}{*}{$0.508(0.722)$} \\
\hline Female & $8(57.1)$ & $6(42.9)$ & $14(43.8)$ & \\
\hline \multicolumn{5}{|c|}{ Diabetes Mellitus } \\
\hline Yes & $4(44.4)$ & $5(55.6)$ & $9(28.1)$ & \multirow{2}{*}{$0.155(0.694)$} \\
\hline No & $12(52.2)$ & $11(47.8)$ & $23(71.9)$ & \\
\hline \multicolumn{5}{|c|}{ Smoking status } \\
\hline Smoker & $3(42.8)$ & $4(57.2)$ & $7(21.9)$ & \multirow{2}{*}{$0.183(0.669)$} \\
\hline Non-smoker & $13(52)$ & $12(48)$ & $25(78.1)$ & \\
\hline \multicolumn{4}{|c|}{ Fibula Fracture } & \\
\hline Present & $14(53.8)$ & $12(46.2)$ & $26(81.3)$ & \multirow{2}{*}{$0.821(0.654)$} \\
\hline Absent & $2(33.3)$ & $4(66.7)$ & $6(18.7)$ & \\
\hline
\end{tabular}

Table 1 shows the distribution of the socio-demographic among the two procedure groups The association between all the above independent variables and the procedure groups was found to be insignificant ( $\mathrm{p}>0.05)$.

\section{Duration of surgery}

Table 2: Association between the type of procedure and duration of surgery

\begin{tabular}{|c|c|c|c|}
\hline \multirow{2}{*}{ Procedure } & \multicolumn{2}{|c|}{ Duration of Surgery (minutes) } & \multirow{2}{*}{ p value } \\
\cline { 2 - 3 } & Mean & SD & \\
\hline Intramedullary nail & 72.19 & 10.483 & \multirow{2}{*}{$<0.001$} \\
\hline Plating & 98.13 & 11.236 & \\
\hline
\end{tabular}

Table 2 The mean duration of surgery among the patients who underwent intramedullary nail was $72.19( \pm 10.483)$ minutes while it was $98.13( \pm 11.236)$ minutes among the patients undergoing plate osteosynthesis by MIPPO technique. There was statistically significant difference $(p<0.001)$ in the time of

surgery between the two procedure groups.

\section{Functional score}

Table 3: Association of the Olreud-Molander Ankle score with the two procedure groups at the end of 6th month

\begin{tabular}{|c|c|c|c|}
\hline \multirow{2}{*}{ Procedure } & \multicolumn{2}{|c|}{ Olreud-Molander Ankle score, } & \multirow{2}{*}{$\begin{array}{c}\mathbf{p} \\
\text { valu) }\end{array}$} \\
\cline { 2 - 3 } & Good & Excellent & \\
\hline Intramedullary nail & $2(12.5)$ & $14(87.5)$ & \multirow{2}{*}{0.019} \\
\hline Plating & $8(50)$ & $8(50)$ & \\
\hline
\end{tabular}

Table 3 There was statistically significant difference $(\mathrm{p}=0.019)$ in the Olreud-Molander Ankle score among the two procedure groups. The patients with intramedullary nail had higher proportions in excellent groups when compared to patients with plating.

\section{Time of Union of fracture}

Table 4: Association between the type of procedure for distal tibial fracture and time of union of the fracture

\begin{tabular}{|c|c|c|c|c|}
\hline \multirow{2}{*}{ Procedure } & \multicolumn{2}{|c|}{ Time of Union (weeks) } & \multirow{2}{*}{ t value } & \multirow{2}{*}{ p value } \\
\cline { 2 - 3 } & Mean & SD & & \\
\hline Intramedullary nail & 19.25 & 3.642 & \multirow{2}{*}{2.639} & \multirow{2}{*}{0.013} \\
\hline Plating & 24.13 & 6.428 & & \\
\hline
\end{tabular}

Table 4 shows the distribution and association of the time for fracture union (In weeks) post-surgery and the type of procedure. The mean time for fracture union among the patients who underwent intramedullary nail was 19.25 $( \pm 3.642)$ weeks while it was $24.13( \pm 6.428)$ weeks among the patients undergoing plate osteosynthesis by MIPPO technique. The time for fracture union among patients who underwent intramedullary nail was significantly less when compared to plating

\section{Complication}

Table 5: Distribution of Complications among the two procedure groups

\begin{tabular}{|c|c|c|}
\hline \multirow{2}{*}{ Complications } & \multicolumn{2}{|c|}{ Type of Procedure n, (\%) } \\
\cline { 2 - 3 } & Intramedullary Nail, $(\mathbf{n}=\mathbf{1 6})$ & Plating, $(\mathbf{n}=\mathbf{1 6})$ \\
\hline Malunion & $1(6.3 \%)$ & 0 \\
\hline Non-union & 0 & $3(18.8 \%)$ \\
\hline Delayed Union & $2(12.5 \%)$ & $2(12.5 \%)$ \\
\hline Infection & 0 & $3(18.8 \%)$ \\
\hline Anterior knee pain & $4(25 \%)$ & 0 \\
\hline
\end{tabular}

Table 5 shows the distribution of the complications following surgery among the two procedure groups. Compared to the participants who underwent intramedullary nail fixation for distal tibial fracture, those with plating had higher proportions of complications such as non-union (18.8\%) and infections (18.8\%) respectively. The proportion of patients with delayed 
union of fracture was equal in both the procedure groups [2(50\%)]. Patients who underwent intramedullary nail for distal tibial fracture had higher proportions of malunion $(6.3 \%)$ and anterior knee pain $(25 \%)$ when compared to plating.

\section{Discussion}

In our study, we compared the two techniques (expert tibial nail and distal tibial medial locking plate fixation) with various parameters like union rate, duration of surgery, rate of complications, and functional outcome using Olreud and Molander score, and RUST score. The time of surgery and fracture union for intramedullary nail was significantly lesser when compared to plating. The Olreud \& Molander scores and RUST scores were significantly higher in patients with IMIL nail. Malunion and anterior knee pain were more frequent after IM interlocking nail. Non-union and infection were found only in the plating group.

In the present study, the mean average age incidence was 44.1 years. The youngest individual was 18 years, and oldest was
80 years. The average age of the patients with distal tibial fracture were similar to the studies done by Kumar YC et al. ${ }^{[13]}$ and Natarajan et al. ${ }^{[14]}$ among similar target population. Hence, distal tibial fractures commonly occur in the age group of 40-50 years.

The functional outcome as assessed by the Olreud-Molander Ankle score were significantly higher in the patients who underwent Intramedullary nailing when compared to the group with plating. More number of patients were in the excellent group $(87.5 \%)$ in the patients with nailing when compared to patients with plating $(50 \%)$. The findings were similar to studies by Vallier HA et al. ${ }^{[7]}$ and Singh A et al. [15]. Similarly, Nandakumar et al. concluded that intramedullary interlocking nailing is a reliable method of treatment for distal metaphyseal tibial fractures with a high union rate and low complication rate $[11,12,10]$.

In the present study, the average period of radiological union was found to be significantly faster in the nailing group which is comparable to Yang et al. ${ }^{[16]}$ existing studies (Table-6).

Table 6: Comparison of radiological union -nailing versus plating

\begin{tabular}{|c|c|c|}
\hline \multirow{2}{*}{ Authors } & \multicolumn{2}{|c|}{ Time of Union } \\
\cline { 2 - 3 } & Nailing & Plating \\
\hline Vallier HA, Le TT, Bedi A $^{[7]}$ & 22.6 weeks & 27.8 weeks \\
\hline Singh A, Kumar R, Ummat V, Pandey PK ${ }^{[15]}$ & 22.6 weeks & 23 weeks \\
\hline Im GI, Tae SK $^{[17]}$ & 18 weeks & 20 weeks \\
\hline Janssen KW, Biert J, kampen A $^{[18]}$ & 21 weeks & 19 weeks \\
\hline Natarajan GB, Srinivasan DK, Vijayaraghavan PV $^{[14]}$ & 24.9 weeks & 24.2 weeks \\
\hline Our study & 19.25 weeks & 24.13 weeks \\
\hline
\end{tabular}

The comparison of the complications of nailing and plating in represented in table 7 and table 8 respectively. the current study with the previous studies have been

Table 7: Comparison of studies-complications of nailing

\begin{tabular}{|c|c|c|c|}
\hline \multirow{2}{*}{ Authors } & \multicolumn{3}{|c|}{ Rate $(\%)$} \\
\hline & Infection & Non-Union & Mal-union \\
\hline Vallier HA, Le TT, Bedi A ${ }^{[7]}$ & $5.3 \%$ & $7.1 \%$ & $23 \%$ \\
\hline Singh A, Kumar R, Ummat V, Pandey PK ${ }^{[15]}$ & 0 & 0 & $15 \%$ \\
\hline Im GI, Tae SK ${ }^{[17]}$ & $2.9 \%$ & 0 & $11.7 \%$ \\
\hline Janssen KW, Biert J, kampen A ${ }^{[18]}$ & 1 & 0 & $20.85 \%$ \\
\hline Natarajan GB, Srinivasan DK, Vijayaraghavan PV [14] & 0 & $6.7 \%$ & $16.65 \%$ \\
\hline Our study & 0 & 0 & $6.3 \%$ \\
\hline
\end{tabular}

Table 83: Comparison of studies- complications of plating

\begin{tabular}{|c|c|c|c|}
\hline \multirow{2}{*}{ Authors } & \multicolumn{3}{|c|}{ Rate (\%) } \\
\cline { 2 - 4 } & Infection & Non-Union & Mal-union \\
\hline Vallier HA, Le TT, Bedi A $^{[7]}$ & $2.7 \%$ & $4.2 \%$ & $8.3 \%$ \\
\hline Singh A, Kumar R, Ummat V, Pandey PK ${ }^{[15]}$ & $10 \%$ & 0 & 0 \\
\hline Im GI, Tae SK $^{[17]}$ & $20 \%$ & $6 \%$ & 0 \\
\hline Janssen KW, Biert J, kampen A $^{[18]}$ & 0 & 0 & $16.7 \%$ \\
\hline Natarajan GB, Srinivasan DK, Vijayaraghavan PV $^{[14]}$ & $6.6 \%$ & 0 & $13.3 \%$ \\
\hline Our study & $18.8 \%$ & $18.8 \%$ & 0 \\
\hline
\end{tabular}

Boos $\mathrm{N}$ et al. ${ }^{[20]}$ in 51 cases of distal tibial fracture with interlocking nail, there was incidence of $16 \%$ malunion. In our comparative study has also described more malalignment after nailing than plating

In our study, delayed union of the fracture was found in equal proportion in both the nailing and plating group. This is comparable to studies conducted by Fan CY et al. ${ }^{[21]}$ and Aso Mohammad et al. ${ }^{[22]}$.

The infection rate was higher in the plating group when compared to nailing. About one fifth of the patients in the plating group had developed infection post-surgery while there was no incidence of infection in the nailing group. Among these patients, two were superficial and were treated with antibiotics. The third infection was deep exposing the plate and was managed by placing a skin flap over the area. The findings were in line with the study done by Kumar YC et al. ${ }^{[13]}$ and Redfern DJ et al. ${ }^{[19]}$.

There were three cases of non-union (18.8\%) in this study. The findings were present only in patients who underwent plating. Two patients with non-union underwent bone marrow 
injection over the fracture site while the third patient underwent iliac bone grafting.

Smokers had higher proportions of non-union, delayed union when compared to non-smokers. Similarly, patients with diabetes mellitus had higher proportions of non-union and infection rates when compared to those without diabetes mellitus.

According to the results in our study, the fracture union rate is faster and malunion rate is higher in the nail group and the infection rate is higher in the plate group leads to complication like wound dehiscence, tendon exposed, implant exposed and implant failure and non-union. Therefore, the multidirectional intramedullary nail is superior to the plate.

\section{Conclusion}

The study found intra-medullary inter-locking (IMIL) nailing was more successful and effective in terms of achieving good union with optimal functional outcomes compared to the extra medullary plating for closed extra-articular distal third tibial fractures. A larger sample size with equal representation in both groups is required for a $\mathrm{p}$ value with higher significance.

\section{Limitations}

The study was done only among a smaller group of patients with distal tibial fracture.

The findings of the study can be applied only to the closed extra-articular type of distal tibial fracture AO type A1, A2 and A3. The findings cannot be generalized to other type of distal tibial fractures AO type B, C, Pilon fractures and open fractures.

\section{Recommendations for future research}

Current results are influenced by selection bias because more severe fractures are often treated differently than less severe ones. Future studies could benefit from any of the following design improvements or additions:

- Comparisons of IM nailing and plate fixation on patients with same fracture type and similar prognostic factors.

- Use of validated outcome measures, including patient reported outcomes that measure function and quality of life.

- Use of clinical outcome assessors who are blinded to treatment.

- Use of studies with sufficient statistical power that are designed to limit bias.

- Well-designed studies of long-term outcomes and impact of rehabilitation programs.

\section{Radiograph for nailing}

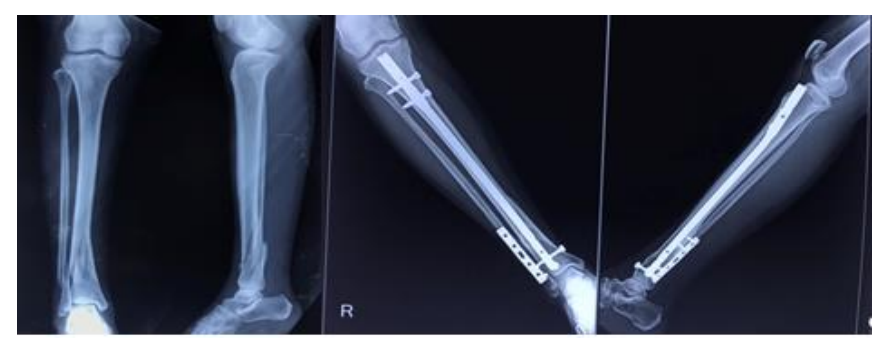

Fig 1: Pre op radiograph shows distal tibia fracture and post op radiograph showing united fracture with nail in situ at end of 5th month

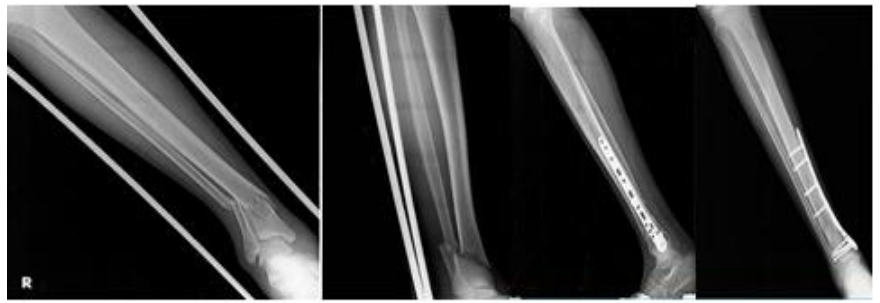

\section{References}

1. Tornetta P, court-Brown C, Heckman JD, McKee M, McQueen MM, Ricci W et al. Rockwood, Green, and Wilkins fractures in adults and children: Eighth edition. 2014, 4026.

2. Bedi A, Le TT, Karunakar MA. Surgical treatment of non-articular distal tibia fractures. J Am Acad Orthop Surg. 2006; 14(7):406-16.

3. McFerran MA, Smith SW, Boulas HJ, Schwartz HS. Complications encountered in the treatment of pilon fractures. J Orthop Trauma. 1992; 6(2):195-200.

4. Wyrsch B, McFerran MA, McAndrew M, Limbird TJ, Harper MC, Johnson KD et al. Operative treatment of fractures of the tibial plafond. A randomized, prospective study. J Bone Joint Surg Am. 1996; 78(11):1646-57.

5. Helfet DL, Shonnard PY, Levine D, Borrelli J. Minimally invasive plate osteosynthesis of distal fractures of the tibia. Injury. 1997; 28(1):A42-7.

6. Tyllianakis M, Megas $\mathrm{P}$, Giannikas D, Lambiris E. Interlocking intramedullary nailing in distal tibial fractures. Orthopedics. 2000; 23(8):805-8.

7. Vallier HA, Cureton BA, Patterson BM. Factors influencing functional outcomes after distal tibia shaft fractures. J Orthop Trauma. 2012; 26(3):178-83.

8. Sarmiento A, Latta LL. 450 closed fractures of the distal third of the tibia treated with a functional brace. Clin Orthop. 2004; (428):261-71.

9. Oh C-W, Kyung H-S, Park I-H, Kim P-T, Ihn J-C. Distal tibia metaphyseal fractures treated by percutaneous plate osteosynthesis. Clin Orthop. 2003; (408):286-91.

10. Mao Z, Wang G, Zhang L, Zhang L, Chen S, Du H et al. Intramedullary nailing versus plating for distal tibia fractures without articular involvement: a meta-analysis. J Orthop Surg. 2015; 10(1):95.

11. Toivanen JAK, Väistö $O$, Kannus $P$, Latvala $K$, Honkonen SE, Järvinen MJ. Anterior knee pain after intramedullary nailing of fractures of the tibial shaft. A prospective, randomized study comparing two different nail-insertion techniques. J Bone Joint Surg Am. 2002; 84-A(4):580-5.92

12. Nandakumar R, Mahapatra S. Use of Intramedullary Nail in Distal Metaphyseal Fractures of Tibia. Int J Sci Stud. 2015; 3(9):4.

13. YK C, SM S, VT. Treatment of distal tibia fractures: plating versus intramedullary nailing. Int J Res Orthop. 2016; 2(3):116.

14. Natarajan G, Vijayaraghavan P, Srinivasan D. Comparison of clinical, radiological, and functional outcome of closed fracture of distal third tibia treated with nailing and plate osteosynthesis. Afr $\mathbf{J}$ Trauma. 2014; 3(2):68.

15. Singh DA, Kumar DR, Ummat DV, Pandey DPK. Comparative Study of Minimally Invasive Plating Versus Nailing In Distal Tibia Metaphyseal Extrarticular Metaphyseal Fractures. IOSR Journal of Dental and Medical Sciences. 2017; 16(9):5-9.

16. Yang S-W, Tzeng H-M, Chou Y-J, Teng H-P, Liu H-H, 
Wong C-Y. Treatment of distal tibial metaphyseal fractures: Plating versus shortened intramedullary nailing. Injury. 2006; 37(6):531-5.

17. Im G-I, Tae S-K. Distal metaphyseal fractures of tibia: a prospective randomized trial of closed reduction and intramedullary nail versus open reduction and plate and screws fixation. J Trauma. 2005; 59(5):1219-23.

18. Janssen KW, Biert J, van Kampen A. Treatment of distal tibial fractures: plate versus nail. Int Orthop. 2007; 31(5):709-14.

19. Redfern DJ, Syed SU, Davies SJM. Fractures of the distal tibia: minimally invasive plate osteosynthesis. Injury. 2004; 35(6):615-20.

20. Boos N, Bugyi I. [Results of locking intramedullary nailing in distal tibial shaft fractures]. Unfallchirurg. 1989; 92(9):453-8.

21. Fan C-Y, Chiang C-C, Chuang T-Y, Chiu F-Y, Chen T$\mathrm{H}$. Interlocking nails for displaced metaphyseal fractures of the distal tibia. Injury. 2005; 36(5):669-74.

22. Mohammed A, Saravanan R, Zammit J, King R. Intramedullary tibial nailing in distal third tibial fractures: distal locking screws and fracture non-union. Int Orthop. 2008; 32(4):547-9. 